\title{
ADOLESCENT HEALTH MONITORING AT THE REGIONAL LEVEL
}

\author{
Adrian Bauman and Lyndall McLellan ${ }^{a}$ \\ Epidemiology Unit \\ South Western Sydney Area Health Service
}

${ }^{a}$ Current address: Needs Assessment and Health

Outcomes Unit, Central Sydney Area Health Service

\section{Anthony Hogan}

Formerly Public Health Officer

NSW Public Health Officer Training Program

Current address: School of Communication Science and Disorders, Cumberland College of Health Sciences, Sydney University

$\mathrm{T}$ his article explores the lack of routinely collected data to support the monitoring of adolescent health. It describes international and local surveys that have been used to fill this information gap. Surveys undertaken in 1992 and 1996 in South Western Sydney are used to illustrate how the information collected can be used to plan and assess local interventions to improve the health of young people.

Adolescence is a time of transition and development, but is also a time when many adopt unhealthy lifestyles and practices that affect their health status. For example, almost all smokers start to smoke in mid-adolescence. However, as teenagers do not use routine health services as frequently as other population groups, few routine population data are collected to permit the regular monitoring of their health. Further, while substantial health system resources are committed to developing adolescent health programs to address areas such as tobacco control, the reduction of hazardous drinking, the reduction of illicit drug use and responsible sexual behaviour, little effort is made to monitor the overall preventive effort to improve adolescent health. ${ }^{1}$

Overseas, routine data collections on adolescent health are carried out in several countries in Europe, as well as in regions within them. These countries use a standardised protocol for collecting a broad range of information about adolescents. This multicentre monitoring study is known as the European World Health Organization Health Behaviour in School Children (HBSC) surveys. ${ }^{2}$ In North America, the routine Youth Risk Behaviour Survey (YRBS) provides State and regional data on diverse adolescent health and behaviour indicators. ${ }^{3}$

Here in Australia, there have been some attempts to collect information describing adolescent health. In NSW, the Health Department conducted a series of drug and alcohol surveys in secondary schools, in 1983, 1986, 1989 and 1992. ${ }^{4}$ This survey was repeated in 1996, but the 1996 survey used slightly different questions from the earlier surveys (to enable the standardisation of all drug and alcohol data collection nationally), and consequently comparisons for trend analyses were not possible. No other aspects of adolescent health are monitored at the State and Area Health Service levels, despite the national investment in interventions across the spectrum of adolescent health needs. One exception to this was the Western Australian Child Health Survey, which assessed a range of child and family indicators and outcomes, but did not focus particularly upon adolescents. ${ }^{5}$

In 1992, South Western Sydney Area Health Service (SWSAHS) was the first regional health service in Australia to collect representative sample population data using the established HBSC adolescent health survey instrument. The survey questions and protocol were adapted from the European survey to conditions in Australia. The survey collected data on mental health, sun protection, injury prevention, physical health, dental health, physical activity and the usual adolescent health-compromising behaviours. A similar adolescent health survey was repeated in the Area in 1996 to assess trends in adolescent health and risk factors. Intersectoral collaboration within health was integral in supporting the conduct of the surveys. Local health promotion and community health teams contacted the randomly sampled schools and collected the data, which were entered and analysed by the Area epidemiology unit. In return, benchmark and trend data were provided by the unit for use in health promotion planning, child health services, drug and alcohol services and Area performance agreements.

Similar surveys were conducted by the Illawarra Public Health Unit in 1996, and across the Western Sydney Catholic education system in 1995. In 1996, a statewide survey of a random sample of adolescents across NSW was carried out using a collaborative process with regional health promotion field staff. The statewide project was managed by a consortium of health promotion managers from NSW. These surveys met regional and State needs, provided good quality epidemiological data and were very low in real costs. None of these studies received any additional Area or State funding, indicating the type of research and monitoring that can be achieved with existing resources. These coordinated regional adolescent surveys are consistent with local planning and can be repeated to monitor health (and risk) trends. For SWSAHS, repeating the population survey allows an estimate of the overall effects of adolescent health programs to be monitored.

As an example, the SWSAHS surveys in 1992 and 1996 are briefly described here. These surveys followed the HBSC protocol and covered school pupils in Years 6, 8 and 10 from randomly sampled schools in the Area. The surveys in 1992 and 1996 sampled 4550 and 3315 pupils respectively, with a balance by sex (overall 49 per cent male) and by school year (33 per cent from Year 6, 36 per cent from Year 8, and 31 per cent from year 10). About a fifth were students born in a non-English-speaking country, 


\section{TABLE 4}

ANALYSIS OF HEALTH TRENDS AMONG YOUTH IN SOUTH WESTERN SYDNEY, 1992-1996

\begin{tabular}{|c|c|c|c|c|}
\hline \multirow[b]{2}{*}{ Content area } & \multirow{2}{*}{$\begin{array}{l}\text { Variable used } \\
\text { as an example }\end{array}$} & \multicolumn{2}{|c|}{ Prevalence rates (\%) } & \multirow[b]{2}{*}{ Comment } \\
\hline & & 1992 & 1996 & \\
\hline Psychosocial and mental health & $\begin{array}{l}\text { Feel lonely } \\
\text { (quite or very often) }\end{array}$ & 16.2 & 10.3 & Apparent decline \\
\hline $\begin{array}{l}\text { Sedentariness and } \\
\text { psychosocial health }\end{array}$ & Watch $>4$ hours TV daily & 41.3 & 37.3 & Little change \\
\hline Injury prevention & Wear bike helmet & 25.5 & 24.7 & No change, low rate \\
\hline Dental health & $\begin{array}{l}\text { Visited dentist } \\
\text { in the past year }\end{array}$ & 61.4 & 50.9 & Decline in routine dental visits \\
\hline $\begin{array}{l}\text { Chronic disease } \\
\text { and management }\end{array}$ & $\begin{array}{l}\text { Medication taken for } \\
\text { asthma in past month }\end{array}$ & 17.1 & 14.6 & $\begin{array}{l}\text { Slight decline, remains } \\
\text { common problem }\end{array}$ \\
\hline Social influences & Mother smokes & 31.0 & 28.6 & Slight decline in role \\
\hline $\begin{array}{l}\text { Source: Trends in adolescent hea } \\
\text { surveys. }{ }^{6}\end{array}$ & in South Western Sydne & & nd 19 & behaviour among school stude \\
\hline
\end{tabular}

reflecting the demographic diversity of the region. The data are more fully described in a report summarising the trends in South Western Sydney youth between 1992 and 1996. ${ }^{6}$ A selection of those data are presented in Table 4 to illustrate the type of question asked and some of the trends observed. These are a very small subset of the domains of the questions asked, but indicate some for which health is deteriorating or continuing at a suboptimal level (such as regular dental health check-ups and continuing low rates of bicycle helmet usage), and some for which there may be some evidence of improvement (such as mental health and social influences for tobacco use). The most commonly reported chronic diseases and their management are also monitored.

In summary, monitoring the health of young people by regional and State surveys can provide a useful framework for assessing the overall effects of our efforts to improve adolescent health. This can provide directions for action to Area health services and to others at the regional level, as well as providing evidence-based feedback on overall progress to date. Using shared resources, such comprehensive monitoring may be feasible and inexpensive at the Area level and provide more useful information than smaller and often inconclusive project evaluations. It is expected that this SWSAHS survey will be repeated at four- to five-year intervals in order to establish trends in adolescent health over a longer period.

\section{REFERENCES}

1. Bauman A, Phongsavan P. Epidemiology of substance use in adolescence: prevalence, trends and policy implications. Drug Alcohol Depend. In press.

2. King A, Wold B, Tudor-Smith C, Harel Y. The health of youth: a cross-national survey. A report of the 1993-94 survey results of health behaviour in school-aged children: a WHO cross-national study. WHO regional publications, European series no. 69. World Health Organization, 1996.

3. Valois RF, Thatcher WG, Drane JW, Reininger BM. Comparison of selected health risk behaviors between adolescents in public and private high schools in South Carolina. J School Health 1997; 67: 434-440.

4. Cooney A, Dobbinson S, Flaherty B. 1992 survey of drug use by NSW secondary students, NSW. Sydney: Drug and Alcohol Directorate, NSW Health Department, 1994.

5. Institute for Child Health. WA child health survey. ABS cat. no. 4303.5. Canberra: AGPS Press, 1995.

6. Bauman A, McLellan L, Young L, Hogan A, et al. Trends in adolescent health in South Western Sydney: report of the 1992 and 1996 health behavour among school student surveys. Sydney: Epidemiology Unit, South Western Sydney Area Health Service, NSW Health Department, 1998. In preparation. 